\title{
Measuring the effects of visual scan codes in advertising
}

\section{David R. Fortin and Kate Surovaya*}

\author{
Department of Management, \\ University of Canterbury, \\ Private Bag 4800 Christchurch, New Zealand \\ Email: david.fortin@canterbury.ac.nz \\ Email: ekaterina.surovaya@canterbury.ac.nz \\ *Corresponding author
}

\begin{abstract}
With smart phone technology becoming increasingly widespread in the consumption space, the use of Visual Scan Codes (VSC) such as QR (Quick Response) or Shazam codes are becoming prominent interactive tools transforming traditional advertising into more engaging and responsive communication platforms. To examine the effects of the presence of these codes, this study uses a $(2 \times 2)$ between-subjects experimental design with treatment groups for code type (QR code active vs. QR code static) and code salience (black and white vs. coloured) with a fifth control group. Findings suggest that such codes have significant effects on hedonic attitudes towards the ad, perceived vividness and brand recall. Participants who noticed the code in the stimulus ad showed higher brand recall and involvement levels. In addition, the mere presence of a static code was found to be perhaps even more effective than an activated code.
\end{abstract}

Keywords: VSC; visual scan codes; QR codes; Shazam; advertising; vividness; involvement; attitudes.

Reference to this paper should be made as follows: Fortin, D.R. and Surovaya, K. (201x) 'Measuring the effects of visual scan codes in advertising', Int. J. Internet Marketing and Advertising, Vol. X, No. X, pp.XX-XX.

Biographical notes: David R. Fortin is currently Associate Professor in Marketing for the Department of Management at The University of Canterbury in New Zealand. He has a PhD in Marketing from The University of Rhode Island (USA) and several years of experience in product management and as a group director in the advertising agency business. His research has been published in outlets such as the Journal of Advertising Research, Journal of Business Research, Advances in Consumer Research, etc. He also wrote chapter contributions in several books about the Web and Global e-Commerce. His research focus is in the area of interactive marketing and e-commerce, consumer research on the web, experimental designs, advertising effectiveness, research methodology, genetically modified foods and attitude change and formation.

Kate Surovaya has a $\mathrm{PhD}$ in Marketing from the University of Canterbury and is an expert in the area of interactive technologies, consumer-generated advertising and creative communication strategies.

This paper is a revised and expanded version of a paper entitled [title] presented at [name, location and date of conference].[AQ1]

AQ1: If a previous version of your paper has originally been presented at a conference, please complete the statement to this effect or delete if not applicable. 


\section{D.R. Fortin and K. Surovaya}

\section{Introduction}

Facilitated by mobile phone technology advancements, Visual Scan Codes (VSC) allow users to use a smartphone to scan a visual cue to interactively gain access to additional information or connect to an external web-based source. QR codes were the first generation of VSC to be used and are short for "Quick Response", meaning that they can be quickly "read" by a smart phone to provide additional useful information related to a product, brand or other objects. Other VSCs include new entrants such as Shazam (Visual Shazaming) who have extended their music recognition technology to also read codes, barcodes and watermarks on fast-moving consumer goods (Riley, 2015; Sparkes, 2015). A QR code represents a two-dimensional matrix-type version of the ubiquitous barcode. The technology originates from Japan; it was developed by Toyota's subdivision and was originally used to track car parts during the manufacturing process (Jackson, 2011). However, the popularity of QR codes came later with the introduction of smart phones enabling the user to scan a code anywhere and from nearly any kind of surface or object. Easy in use, the QR code found its application in many areas: in medicine for issuing prescriptions and patient identification (Lin et al., 2012), in education for engaging students through new multimedia materials (Law, 2012; Ozcelik and Acarturk, 2011), in museums for delivering information about exhibited items (Canadi et al., 2010), in libraries for quick access to information and e-books downloading (Lamb and Johnson, 2013; Lo et al., 2013), even in train tickets in China, on business cards and personalised T-shirts.

With the introduction of smart phones, QR codes have provided an opportunity to turn any traditional advertising into interactive; they have appeared in print, outdoor (Xue and Hairong, 2008) and TV advertising (BusinessWire, 2012; Kim and Yu, 2013), as well as on many packaged goods. Having a sizeable data capacity - up to 4296 alphanumeric characters (Lisa and Piersantelli, 2008), QR codes can trigger consumer actions of differing levels of complexity from simply connecting the user to a company website or downloading a discount voucher to engaging in real-time games. A novel example can be seen from a Sony campaign devoted to the launch of a James Bond movie "Quantum of Solace" (Hamidi, 2008). This campaign required participants to act as spies and collect pieces of information by scanning QR codes appearing on posters.

Now, when any physical object has become potentially clickable (Baker, 2010), QR codes are consumer's portal to a digital world (Baik et al., 2010). Connecting physical and digital worlds by the means of mobile tagging (Canadi et al., 2010; Schmidmayr et al., 2008), QR codes have changed traditional PUSH model of communication to the PULL model where the receiver is able to interact and engage with a brand.

Although there are several studies devoted to the acceptance of QR code technology (Okazaki et al., 2011; Okazaki et al., 2012; Shin et al., 2012; Watson et al., 2013), little is known about the effects of QR codes. The research has shown that $2 \mathrm{D}$ bar codes may enhance learning (Ozcelik and Acarturk, 2011). It was found that the attitudes towards advertising with QR codes or QR code loyalty programs are likely to be more positive in low involvement than in high involvement conditions (Narang et al., 2012; Okazaki et al., 2013). However, when consumers are concerned with privacy disclosure or delayed rewards (Okazaki et al., 2013), or experience social anxiety from scanning a QR code in public places, they may become less loyal in comparison with inactive consumers (Okazaki et al., 2012; Okazaki et al., 2012; Okazaki et al., 2013). Although there was found to be no significant main effect of QR code on attitude towards the ad, attitude towards the brand and purchase intention (Veenis, 2012), in specific consumption 


\section{Measuring the effects of visual scan codes in advertising}

situations such as consumption of environmentally friendly and sustainable products (Atkinson, 2013) and at the real estate market (Burke et al., 2013), QR codes were found to add value to the consumer experience.

The present study is aimed to extend our understanding of the effects of VSC codes in advertising. Specifically, the focus of this research is on the estimation and interpretation of the signalling effects of VSC codes, not dissimilar to the signalling effects of web addresses when they were considered a novelty in advertising about 25 years ago, in the early age of the internet (Maddox and Mehta, 1997).

\section{Theoretical background}

\subsection{Visual scan codes and proximity marketing}

QR codes are one of the first visual scan codes that offered to link the physical and digital worlds. QR codes were invented in 1994 by Denso Wave, the division of Toyota Motor Corporation. They were designed to quickly scan vehicles during the manufacturing process to check if all the automobile parts were in correct locations (FreeQRCodes, n.d.). Very soon QR codes found their application in a much broader context, including tracing food and pharmaceutical products as well as mobile marketing (QRCode, n.d.). QR codes have been common in consumer advertising as they provide a way to access the brand's website faster than by manually entering a URL address in a browser. In addition, QR codes allowed virtual shops to be created, where consumers could purchase goods by scanning the barcodes directly from ads or full-size images of supermarket shelves (Shop2mobi, 2012).

QR codes have contributed to the growth of proximity marketing, which can be defined as localised wireless distribution of advertising available at a particular place (Petro, 2014). Individuals present at that specific location can receive marketing content via Wi-Fi or Bluetooth or through mobile tagging (Petro, 2014). In addition to QR codes, many other types of visual scan codes were developed, such as: Digimark, Blippar, SnapTag, Google Goggles and Microsoft Tag (Butler, 2014). One of the recent innovations is Shazam. It was originally created as an app that recognises the audio from music and identifies what song is currently playing (O'Brien, 2016). This technology has been also used in TV commercials and in-store promotions to engage consumers by sending exclusive brand content (O'Brien, 2016). Likewise, augmented reality is becoming an increasingly popular proximity marketing tool. For instance, it allows a promotional poster to be transformed into a video when viewing with a mobile or tablet camera (Brown, 2014).

Around 2012-2014, QR codes received serious criticism in the press. Adoption of this technology among the general population appeared to be slow for multiple reasons. Firstly, the experience of tagging a QR code was not standardised, and mobile phones had no pre-installed QR code readers (Savitz, 2012). Meanwhile, scanning QR codes required some time and effort, and may have been confusing even for tech-savvy customers (Brown, 2014). It was noted that consumers were moving away from barcodes because mobile barcode-linked content was poorly aligned with consumer expectations (eMarketer, 2012). Often advertisers have used QR codes as a simple link to a company website (Wilkerson, 2012). However, in most cases, consumers expect to receive a discount or a gift after following a barcode (O'Neill, n.d). The experience might be even more disappointing if a QR code is linked to a website not optimised for smartphones (Strout, 2013). 


\section{D.R. Fortin and K. Surovaya}

Sceptics have been recently concerned with the security risks related to QR codes. Hackers can use a QR code for various malicious purposes, such as phishing, which involves creating fake posters with $\mathrm{QR}$ codes and redirecting consumers to fake "phishing" websites, where their passwords are compromised (Infosec, 2015). Through the use of illegitimate QR codes, scammers are able to access a consumer's phone camera, microphone, GPS, obtain sensitive data (password, files, contacts and transactions), read personal emails and text messages, and send out premium texts at high fees (Infosec, 2015).

After a period of stagnation, a new wave of interest towards QR codes was instigated by introduction of wearable devices, such as smart watches and smart glasses (Schneider, 2016). QR codes are seen as more effective in increasing interactivity between real world and digital life for "wearers", since wearable devices make the process of VSC scanning more effortless (Schneider, 2016). The future of QR codes might be associated with the new technologies, such as: 3D holograms embedded in QR codes (Mack, 2014) and a new generation of messengers (Griffith, 2016).

\subsection{QR codes and web address signal effects}

Since QR codes and web addresses have a similar interactive nature and functionality, their effects may be possibly similar. In the early days of the emerging internet, adding a web address to an advertisement was perceived as a novelty. Back then the Journal of Advertising Research published a study by Maddox and Mehta (1997) who discovered that $91 \%$ of respondents perceived advertisers with URLs as being more high-tech and $71 \%$ viewed them as being more sophisticated (Maddox and Mehta, 1997). The authors argued that companies could improve their image by simply including a web-address in their advertisements (Maddox and Mehta, 1997). Even if consumers do not use the mentioned URLs, they would perceive ads containing web addresses as more "customeroriented", "high-tech", and "sophisticated" (Maddox and Mehta, 1997, p.54) suggesting some kind of signalling effect.

\subsection{Dual-process model of interactivity effects}

A Dual-process model of interactivity effects developed by Liu and Shrum (2009) explains why exposure to interactive features may work as well as actually using them, and in some cases even be more powerful (Liu and Shrum, 2009). According to their model, under different circumstances interactivity may either enhance or inhibit persuasion. More specifically, in low involvement conditions the mere presence of interactivity serves as a peripheral cue and is likely to produce favourable attitudes. Under high involvement, however, actual engaging in interactivity may have one of two outcomes - positive or negative. In the first case, depending on personal and situational factors, interactivity may play a facilitating role by enhancing information processing, consequently leading to more positive attitudes. In the second case, interactivity may play an inhibiting role by occupying a person's processing resources, creating difficulties on the way to task completion and consequently, resulting in rather negative attitudes (Liu and Shrum, 2009). The certain expectations of what the interactive capability can deliver could also possibly lead to negative attitudes if that feature under-delivers on that promise (Liu and Shrum, 2009). 


\section{Measuring the effects of visual scan codes in advertising}

\section{Conceptual model and hypotheses}

Drawing from the literature, this study proposes a model of effects of a VSC code in advertising (see Figure 1). To verify our general model, we choose the most common form of current VSC, the QR code to validate our proposed framework. Following exposure to an advertisement with or without a QR code, a consumer is expected to experience differences in attitudes $(\mathrm{H} 1)$, perceived vividness $(\mathrm{H} 2)$ and $\mathrm{QR}$ code recall (H3). QR code recall in turn is predicted to increase advertising involvement (H4) and brand recall level (H5). The development of the hypotheses is presented below.

Figure 1 Conceptual model: potential effects of a VSC code in advertising

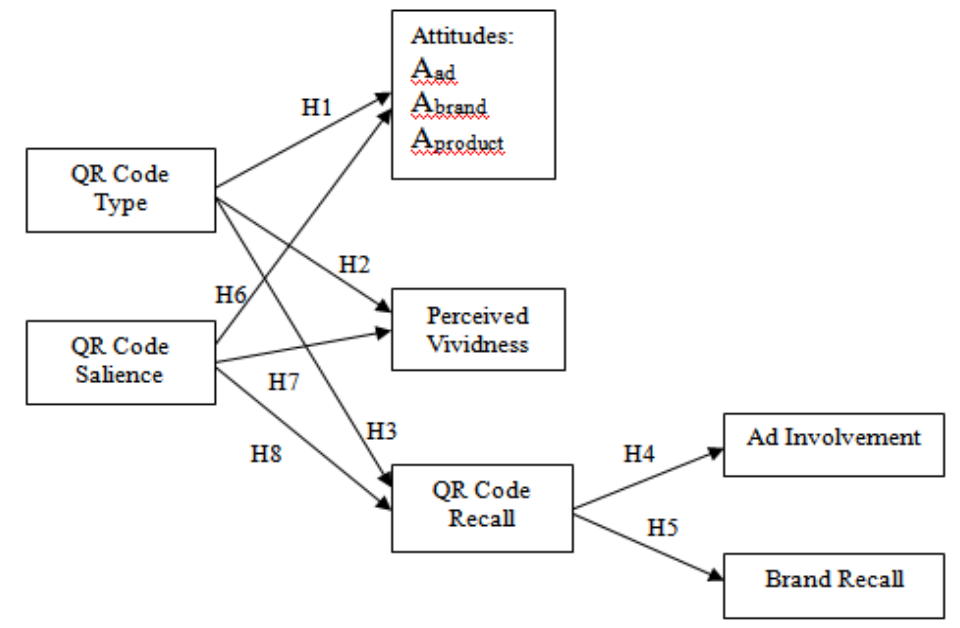

A QR code is a tool that transforms traditional advertising into more engaging and interactive communication platforms by enabling three key features of interactivity: two-way communication, user's control and synchronicity (Johnson et al., 2006; Liu and Shrum, 2002; McMillan and Hwang, 2002; Rafaeli, 1988; Rice and Williams, 1984; Williams et al., 1988; Wu et al., 2010). Because interactivity produces more positive attitudes than non-interactive environments (Cho, 2004; Chung and Zhao, 2004; Fortin and Dholakia, 2005; Teo et al., 2003), it is hypothesised that:

H1: An active QR code connected to a website will produce more favourable Attitude towards the ad $\left(A_{a d}\right)$ than a static not connected $Q R$ code

By connecting traditional offline media with online resources, a QR code is capable of enhancing the richness of the consumer experience. Thus, traditional advertising gains a feature which previously was related only to online interactive advertising - vividness. Vividness is referred to "the representational richness of a mediated environment as defined by its formal features; that is, the way in which an environment presents information to the senses" (Steuer, 1992, p.81). Vividness relates to the breadth and depth of the message. Here, breadth means the number of sensory dimensions such as colours, graphics, sounds, and depth refers to the quality of the presentation (Steuer, 1992). Because QR codes increase the number of sensory dimensions of the message communicated to the consumer, it can be suggested that a $\mathrm{QR}$ code may increase perceived advertising vividness: 


\section{D.R. Fortin and K. Surovaya}

H2: An active QR code connected to a website will produce higher perceived ad vividness than a not connected static $Q R$ code

It has been established by research in social psychology that learning for novel stimuli occurs faster than for familiar stimuli (Lubow and Moore, 1959). Because of the novelty factor, it is expected that consumers will notice and remember a QR code in the stimulus ad. Therefore:

H3: An active $Q R$ code will be positively related to $Q R$ code recall

Because interactivity was found to have a positive effect on advertising involvement (Fortin and Dholakia, 2005; Zhenhui et al., 2010), it follows that people who noticed the presence of a QR code in an ad, are likely to be more involved:

\section{H4: QR code recall will be positively related to advertising involvement}

The previous research has found that interactivity has positive effect on consumer's memory (Ariely, 2000; Chung and Zhao, 2004). As explained by these scholars, the effect of increased memory is facilitated by the user's control over the information flow occurring in the interactive environment (Chung and Zhao, 2004) and is especially profound when processing resources are sufficiently high (Ariely, 2000). Therefore, it may be hypothesised that:

\section{H5: QR code recall will be positively related to brand recall}

Because of the widespread belief that coloured or unusually looking QR codes perform better that traditional black-and-white QR codes and because of continuous experimentations with QR codes' designs at the market (Chu et al., 2013; Lin et al., 2013), the proposed theoretical framework also incorporates QR Code Salience and proposes to test its effects on major advertising response variables (H6-H8). Following the argumentation of visual salience theories, it is suggested that a more salient QR code is more likely to attract consumer's attention (Guido, 2001; Michael and Gálvez-García, 2011; Schubö, 2009; Wolfe, 2001). Also, because colour in advertising was found to increase arousal and enhance recall (Warner and Franzen, 1947), it is hypothesised that:

H6: Coloured QR codes will produce more favourable Attitude towards the ad $\left(A_{\text {ad }}\right)$ than black and white $Q R$ codes

H7: Coloured QR codes will result in higher perceived ad vividness than black and white QR codes

H8: Coloured $Q R$ codes will create higher $Q R$ code recall than black and white $Q R$ codes

The suggested hypotheses will be tested using experimental approach which is discussed in the following sections.

\section{Methodology}

In order to test the proposed hypotheses, this study uses a $(2 \times 2)$ between subjects experimental design with treatment groups for VSC code type (QR code active vs. static) and code salience (black and white vs. coloured) with a fifth control group generating five experimental conditions in an incomplete between subjects factorial design. The 


\section{Measuring the effects of visual scan codes in advertising}

experimental approach was selected as it is the best recommended procedure to study consumer response in online environments (Fortin and Ballantine, 2009). The control group will serve as a baseline measure to compare the effects of the stimulus ad without the presence of a QR code.

\subsection{Procedure}

Participants were invited to an online experiment where they were randomly assigned to one of five treatment groups. Survey instructions stated that participants would be asked for their opinions about a new print magazine. They would need to first flip through several pages of a flash-based magazine and then answer a set of corresponding questions. Being randomly assigned to one of four experimental conditions or to the control group, participants were exposed to the same Coca-Cola Zero print ad inserted in the mock magazine with different QR-code variations as per the treatment groups: active or static QR code, black and white or coloured QR code. Respondents from the control group were exposed to the same ad but without a QR code. To avoid the possibility that participants may not have access to a smart phone or QR code reading application, the procedure allowed respondents to mouse click on the QR code instead of scanning it with a smart phone (see Figure 2). To facilitate this, the connected QR codes were accompanied by the visual note 'Click on the QR code to learn more'. The connected QR codes were linked to a specifically created web-page which contained entertaining information about Coca-Cola Zero. This information consisted of a newly released Hollywood movie called Battleship and a Coca-Cola video ad utilising this Battleship theme. Meanwhile, the not connected QR code was not linked to any web-page. The given QR codes were shown as black and white or in colour with a Coca-Cola logo inside it.

Figure 2 Stimulus material

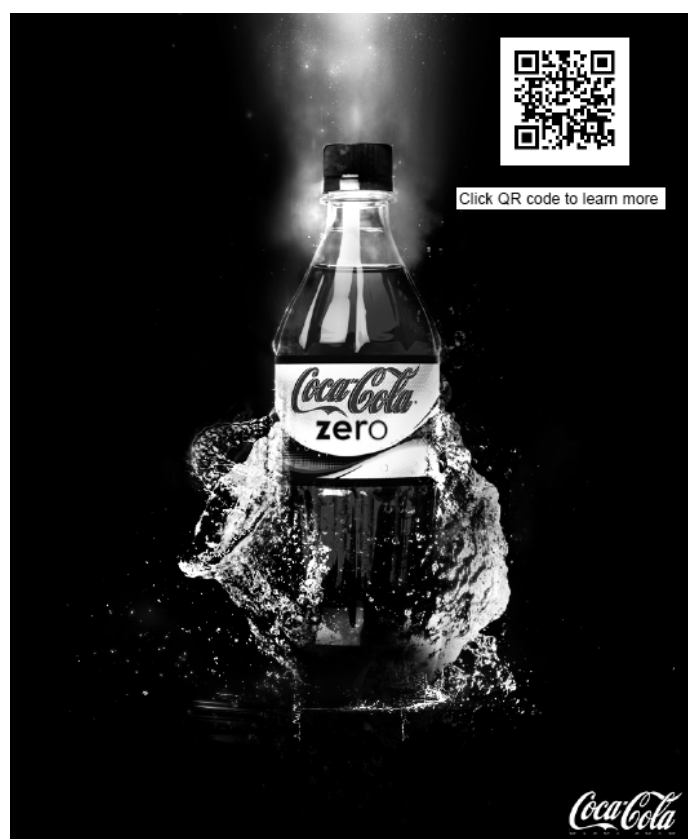




\section{D.R. Fortin and K. Surovaya}

\subsection{Measurements}

The study used existing scales used in similar studies in the literature such as Attitude towards the ad $\left(\mathrm{A}_{\mathrm{ad}}\right)$ (Batra and Ahtola, 1991; Voss et al., 2003), Attitude towards the brand $\left(\mathrm{A}_{\text {brand }}\right)$ (MacKenzie et al., 1986), Perceived vividness (Steuer, 1992), Attitude towards the product (Underwood and Klein, 2002), and Advertising involvement (Lee, 2000). All Cronbach alpha values ranged from .805 to .925 , revealing internal consistency and reliability of the scales.

\section{Results}

A total of 210 respondents fully completed the online experiment and were recruited online through social media groups. Participants were offered a chance to win a movie voucher as an incentive to join the study. The obtained sample consisted of 127 females $(60.5 \%)$ and 83 males (39.5\%). Respondents' ages ranged from 18 to 65 , with a total of $61 \%$ of the sample being in 18-24 age group. Meanwhile, respondents between 25 and 34 years old $(20.5 \%)$ represented the second largest group in the sample, following by 34-45 years olds $(10 \%)$. Regarding annual household income, nearly half of the respondents (47.6\%) described themselves as being in the middle third of the population.

The click through statistics provided by Google Analytics indicated that a total of 14 respondents $(16 \%)$ attempted to actually mouse click at the QR code during the experiment. The relatively small click through rate may be explained by the overall lack of understanding of $\mathrm{QR}$ codes among the population observed by other researchers (Sago, 2011) which is determined by perceived information value of QR code advertising, its entertainment value and perceived ease of use (Jong-Hyuok et al., 2012).

Hypotheses $\mathrm{H} 1-\mathrm{H} 3$ and $\mathrm{H} 6-\mathrm{H} 8$ were tested using MANCOVA. QR Type and QR Code Salience were entered as independent variables. Meanwhile, attitude towards the ad, perceived vividness and $\mathrm{QR}$ code recall were entered as dependent variables. The data were examined for normal distribution using the skewness and kurtosis procedure, and for homogeneity using a Box's $\mathrm{M}$ test. To address an incomplete factorial design which, in fact, includes a $2 \times 2$ specified design with an extra cell representing a control group, Type IV sum of squares was selected instead of the default Type III method. The $\mathrm{A}_{\mathrm{ad}}$ scale was deconstructed into the cognitive and hedonic components as per Spangenberg et al. (1997) and included in the analysis.

The MANCOVA revealed a significant main multivariate effect for type of $\mathrm{QR}$ code, Wilks' $\lambda=.919, \mathrm{~F}(3,202)=5.974, \mathrm{p}<.001, \eta_{\mathrm{p}}{ }^{2}=.081$. At the univariate level (see Table 1), the QR code type showed a significant effect on hedonic attitude towards the ad, $\mathrm{F}(1,204)=9.411, \mathrm{p}<.005, \eta_{\mathrm{p}}{ }^{2}=.044$; perceived vividness, $\mathrm{F}(1,204)=9.293$, $\mathrm{p}<.005, \eta_{\mathrm{p}}{ }^{2}=.044$, and $\mathrm{QR}$ code recall, $\mathrm{F}(1,204)=5.155, \mathrm{p}<.05, \eta_{\mathrm{p}}{ }^{2}=.025$. The pattern of the QR code's effects appeared to be similar for all three significant dependent variables with the static QR code generating the most positive effect (see Figure 3). A further LSD Post Hoc test suggests that the static QR code outperforms the active code connected to a website. Specifically, the static QR code has a greater positive impact on hedonic attitude towards the ad $\left(\mathrm{M}_{\text {mean difference }}=.6696, \mathrm{p}<.001\right)$, vividness $(\mathrm{M}=.3968$, $\mathrm{p}<.005)$ and $\mathrm{QR}$ code recall $(\mathrm{M}=.14, \mathrm{p}<.05)$ than the active bar code. However, results do not show statistically significant effects for QR code salience. 
Measuring the effects of visual scan codes in advertising

Table 1 MANCOVA analysis: tests of between-subjects effects

\begin{tabular}{|c|c|c|c|c|c|c|c|}
\hline Source & $\begin{array}{l}\text { Dependent } \\
\text { Variable }\end{array}$ & $\begin{array}{c}\text { Type IV } \\
\text { Sum of Squares }\end{array}$ & $d f$ & $\begin{array}{l}\text { Mean } \\
\text { Square }\end{array}$ & $F$ & Sig. & $\begin{array}{l}\text { Partial Eta } \\
\text { Squared }\end{array}$ \\
\hline \multirow{3}{*}{$\begin{array}{l}\text { Corrected } \\
\text { Model }\end{array}$} & Hedonic_at_ad & $27.534^{\mathrm{a}}$ & 5 & 5.507 & 3.178 & .009 & .072 \\
\hline & Vividness & $7.346^{\mathrm{b}}$ & 5 & 1.469 & 2.210 & .055 & .051 \\
\hline & QR_code_recall & $15.608^{\mathrm{c}}$ & 5 & 3.122 & 18.201 & .000 & .308 \\
\hline \multirow{3}{*}{ Intercept } & Hedonic_at_ad & 1111.693 & 1 & 1111.693 & 641.607 & .000 & .759 \\
\hline & Vividness & 731.714 & 1 & 731.714 & 1100.462 & .000 & .844 \\
\hline & QR_code_recall & 17.330 & 1 & 17.330 & 101.047 & .000 & .331 \\
\hline \multirow{3}{*}{ Education } & Hedonic_at_ad & 7.848 & 1 & 7.848 & 4.529 & .035 & .022 \\
\hline & Vividness & .535 & 1 & .535 & .804 & .371 & .004 \\
\hline & QR_code_recall & .036 & 1 & .036 & .212 & .646 & .001 \\
\hline \multirow{3}{*}{ QR_code } & Hedonic_at_ad & 16.306 & 1 & 16.306 & 9.411 & .002 & .044 \\
\hline & Vividness & 6.179 & 1 & 6.179 & 9.293 & .003 & .044 \\
\hline & QR_code_recall & .884 & 1 & .884 & 5.155 & .024 & .025 \\
\hline \multirow{3}{*}{ Colour } & Hedonic_at_ad & .018 & 1 & .018 & .011 & .918 & .000 \\
\hline & Vividness & .003 & 1 & .003 & .004 & .950 & .000 \\
\hline & QR_code_recall & .095 & 1 & .095 & .555 & .457 & .003 \\
\hline \multirow{3}{*}{$\begin{array}{l}\text { QR_code* } \\
\text { Colour }\end{array}$} & Hedonic_at_ad & .480 & 1 & .480 & .277 & .599 & .001 \\
\hline & Vividness & .026 & 1 & .026 & .039 & .844 & .000 \\
\hline & QR_code_recall & .224 & 1 & .224 & 1.309 & .254 & .006 \\
\hline \multirow{3}{*}{ Error } & Hedonic_at_ad & 353.465 & 204 & 1.733 & & & \\
\hline & Vividness & 135.643 & 204 & .665 & & & \\
\hline & QR_code_recall & 34.987 & 204 & .172 & & & \\
\hline \multirow{3}{*}{ Total } & Hedonic_at_ad & 4178.375 & 210 & & & & \\
\hline & Vividness & 2915.222 & 210 & & & & \\
\hline & QR_code_recall & 125.000 & 210 & & & & \\
\hline \multirow{3}{*}{$\begin{array}{l}\text { Corrected } \\
\text { Total }\end{array}$} & Hedonic_at_ad & 380.999 & 209 & & & & \\
\hline & Vividness & 142.989 & 209 & & & & \\
\hline & QR_code_recall & 50.595 & 209 & & & & \\
\hline
\end{tabular}

Notes: $\quad * \mathrm{R}$ Squared $=.072($ Adjusted R Squared $=.050)$.

$\mathrm{R}$ Squared $=.051$ (Adjusted R Squared $=.028)$.

$\mathrm{R}$ Squared $=.308$ (Adjusted R Squared $=.292)$.

Hypotheses H4 and H5 were tested using the independent sample t-tests. QR code recall was entered as independent variable. Meanwhile, advertising involvement and brand recall were entered one by one as dependent variables.

H4 states that QR code recall is positively related to advertising involvement. Results demonstrate that consumers who remembered noticing the $\mathrm{QR}$ code are significantly more involved in the advertisement than those who did not notice the code: $\mathrm{t}=-3.142$, $\mathrm{df}=208, \mathrm{p}<.005, \mathrm{M}_{\text {noticed }}=3.3827, \mathrm{M}_{\text {did not notice }}=2.7961$.

$\mathrm{H} 5$ states that QR code recall is positively related to brand recall. Results indicate that participants who remembered noticing the QR code demonstrate a significantly higher brand recall as opposed to those who did not notice the barcode: $\mathrm{t}=-2.211$, $\mathrm{df}=159.966$, $\mathrm{p}<.05, \mathrm{M}_{\text {noticed }}=2.12, \mathrm{M}_{\text {did not notice }}=1.82$. 
D.R. Fortin and K. Surovaya

Figure 3 Profile plots: effects of QR code type

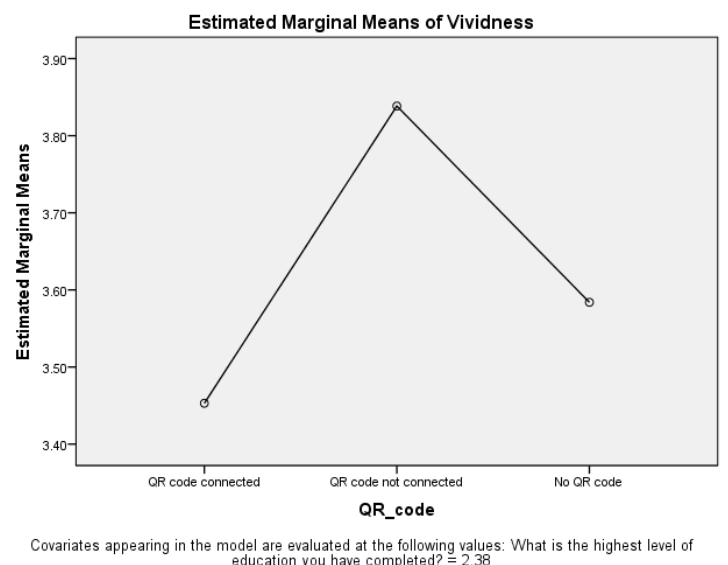

(a) Perceived Vividness

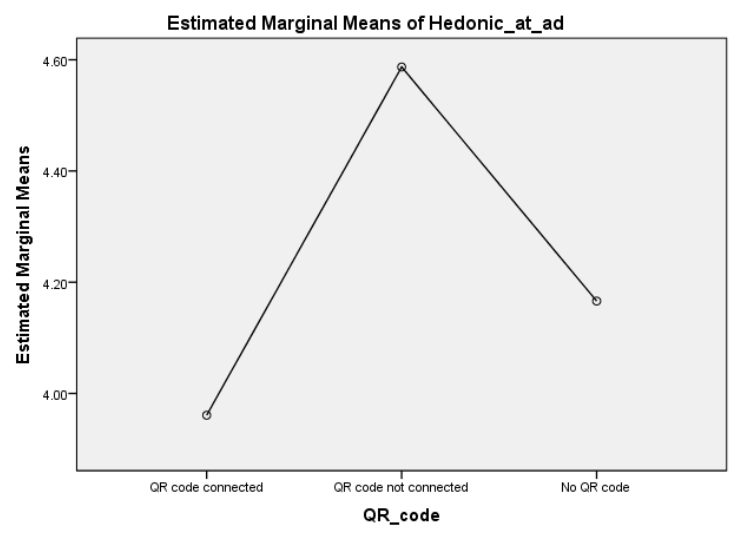

Covariates appearing in the model are evaluated at the following values: What is the highest level of
education you have completed?

(b) Hedonic $\mathrm{A}_{\mathrm{ad}}$

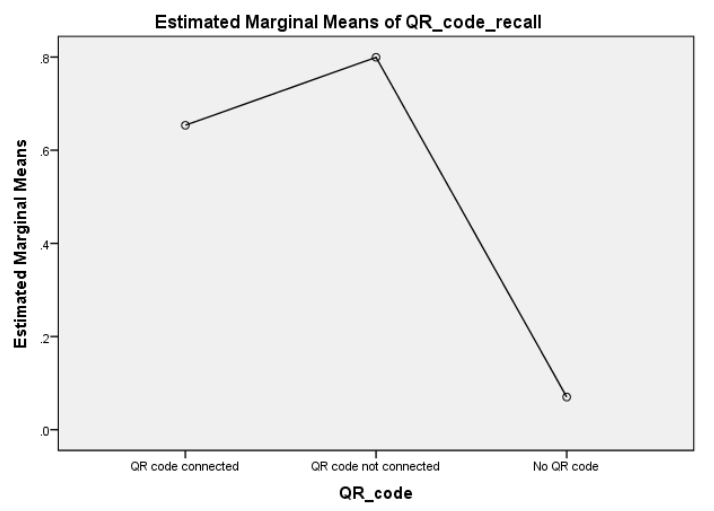

Covariates appearing in the model are evaluated at the following values: What is the highest level of
education you have completed? $=2.38$

(c) QR Code Recall 


\section{Measuring the effects of visual scan codes in advertising}

Education was found to be a significant covariate at the univariate level for hedonic attitude towards the ad, $\mathrm{F}(1,204)=4.529, \mathrm{p}<.05, \eta_{\mathrm{p}}{ }^{2}=.022$. In particular, hedonic attitude towards the stimulus ad with a QR code was found to be more favourable for individuals with either lowest $\left(\mathrm{M}_{\text {high school }}=4.479, \mathrm{M}_{\text {college }}=4.483\right)$ or highest levels of education $\left(\mathrm{M}_{\mathrm{PhD}}=4.444\right)$ rather than for most university graduates $\left(\mathrm{M}_{\text {bachelor degree }}=3.935\right.$, $\left.\mathrm{M}_{\text {postgraduate diploma }}=4.092, \mathrm{M}_{\text {masters degree }}=4.029\right)$.

\section{Discussion}

This study contributes to advertising theory by extending our understanding of the effects of VSC codes in five significant ways. Firstly, while most of the previous literature on QR codes is focused on technology acceptance and users' motivations, few studies have examined their influence on advertising effectiveness, which is the focal point of this study. The present research was designed to investigate the effects of QR code Type and Salience on a wide range of consumer responses. Secondly, the present study proposes a conceptual model of QR code's effects in advertising which includes a range of direct and indirect effects. The experiment showed that a QR code impacts positively on hedonic attitude towards the ad, perceived vividness and QR code recall. Thirdly, the results highlight a difference between those respondents who can remember noticing the QR code in the advertisement and those who didn't. It appeared that the participants who noticed the code were significantly more involved in the ad and then showed higher brand recall afterwards. Fourthly, findings suggest that a static QR code can be as or even more effective than an active QR code. This is counter-intuitive but does support previous research by Liu and Schrum (2009). It implies that when consumers notice a QR code available in the ad, but do not scan it, they can form more positive attitudes towards this ad. This is consistent with web address research from the 90's (Maddox and Mehta, 1997); that is, signalling of what the code provides is perhaps more powerful that what it actually delivers as a benefit. Finally, the data shows no significant difference for vividness effects of a coloured QR code and a standard black and white QR code. Thus, it seems that $\mathrm{QR}$ code salience in terms of creative tactics may not affect advertising effectiveness in a significant way.

Overall, the findings bring into question the expectation that the effects of a visual stimulus such as a VSC will always be positive. Rather, the findings support the Dualprocess model of interactivity effects (Liu and Shrum, 2009). In this study, a low involvement condition was considered when a consumer had a QR code available, but did not use it. Findings indicate that under low involvement conditions, responses to the ad with a $\mathrm{QR}$ code are likely to be positive. In this study, a high involvement condition was considered when a person actually scanned a QR code. Results show that under high involvement, the barcode may play an inhibiting role and therefore, can do more harm than good.

Perhaps an explanation for this phenomenon is the participant's disappointment resulting from the information consumers received after reading the code. This is supported by numerous observations reported in the media (Brown, 2014; eMarketer, 2012; O’Neill, n.d.; Strout, 2013; Wilkerson, 2012). As defined by Bell (1985) disappointment is a "psychological reaction to an outcome that does not meet a decision maker's priori expectation" (as cited in van Dijk et al., 2003, p.506). It is related to "the sense of loss or gain incurred by resolution of a chosen alternative" (Bell, 1985, p.117). The advertisement used in the present experiment resembles the majority of QR code ads 


\section{D.R. Fortin and K. Surovaya}

in the market which provide non incentive-based content (Okazaki et al., 2011). Previous research, however, shows that most consumers expect to get an incentive after reading a QR code such as a discount or a product sample (Okazaki et al., 2011). Thus, it may be inferred that consumers are generally disappointed by QR codes and what they deliver in added value.

This is consistent with studies demonstrating that information quality is the main driver for using QR codes (Jong-Hyuok et al., 2012; Shin et al., 2012). Shin (2012) states that for QR codes, it is not enough to be responsive. He defines information quality as "the quality users experience during an interaction; that is, how the users obtain the information they want and what kind of quality information/services they receive" (Shin et al., 2012, p.1424). He argues that consumers will not accept QR code technology, unless after scanning they gain some form of quality information (Shin et al., 2012).

In fact, consumers can anticipate their disappointment of the information allocated behind the QR codes. According to Theory of Disappointment, potential disappointment has a greater impact on preference than potential satisfaction which implies risk aversion for the decision maker (Bell, 1985). Therefore, consumers may try to avoid risk of scanning the code to prevent their unpleasant psychological reaction. This explains the relatively low click-through rate $(16 \%)$ of the QR code in the present experiment and also provides an additional explanation of why the mere presence of an inactive QR code appeared to be even more effective than an activated QR code.

\section{Managerial implications}

Apart from the theoretical insights provided by the present research, this study offers useful implications for practitioners who wish to incorporate VSC codes into their advertising campaigns. Based on the findings, firms may use VSC codes in traditional advertising to increase perceived vividness, hedonic attitude towards the ad, ad involvement and brand recall. Secondly, use of either black-and-white or coloured versions of a QR code does not appear to influence advertising effectiveness. Thirdly, marketers should focus on designing useful and relevant information which will be encoded in the QR code to meet consumer's expectations. It may be worthwhile to provide a hint of what valuable information is to be found behind the code. Fourthly, advertisers should not expect that large numbers of consumers will actually scan the QR code, but rather use QR codes as a signal to enhance brand imagery. In order to attract attention to the QR code, it needs to be visible and recognisable as a component of the ad. Even if individuals do not scan the code, they are more likely to be involved with the ad and better remember the brand after exposure.

\section{Limitations and future research}

Future research should attempt to replicate these seminal results with other product categories and with a wider range of advanced digitally-based benefits as technology improves over time. Also, further research should examine the effect of incorporating other types of VSCs such as the new Shazam codes (Riley, 2015) in different forms of advertising and on packaging designs. The present study has employed the stimulus ad where a QR code represented an independent element not related to the ad concept. However, a VSC code incorporated in the advertisement's creative concept might be the 


\section{Measuring the effects of visual scan codes in advertising}

focus of further theoretical development. In this study, participants had a choice to click or not to click on a visible QR code. Future experiments could use a different procedure to avoid possible self-selection biases.

\section{References}

Ariely, D. (2000) 'Controlling the information flow: effects on consumers' decision making and preferences', Journal of Consumer Research, Vol. 27, No. 2, pp.233-248. doi: $10.1086 / 314322$

Atkinson, L. (2013) 'Smart shoppers? Using QR codes and 'Green' smartphone apps to mobilize sustainable consumption in the retail environment', International Journal of Consumer Studies, Vol. 37, No. 4, pp.387-393.

Baik, S., Oh, Y., Yu, G., Sohn, J., Jo, D. and Ji, Y. (2010) 'Rethinking QR Code: analog portal to digital world', Multimedia Tools and Applications, Vol. 58, No. 2, pp.427-434.

Baker, L. (2010) 'Making physical objects clickable: using mobile tags to enhance library displays', Journal of Library Innovation, Vol. 1, No. 2, pp.22-28.

Batra, R. and Ahtola, O.T. (1991) 'Measuring the hedonic and utilitarian sources of consumer attitudes', Marketing Letters, Vol. 2, No. 2, pp.159-170.

Bell, D.E. (1985) 'Putting a premium on regret', Management Science, Vol. 31, No. 1, pp.117-120.

Brown, M. (2014) Is the QR Code Dead? Available online at: http://www.pfsweb.com/blog/is-theqr-code-dead (accessed on 31 August 2016).

Burke, M.E., O'Callaghan, S. and Quigley, M. (2013) 'The business of digital storytelling: augmenting information systems with QR codes', Journal of Systems and Information Technology, Vol. 15, No. 4, pp.347-367.

BusinessWire (2012) Innovative Super Bowl 1st Caps A Record Go Daddy Performance. Available online at: http://www.businesswire.com/news/home/20120205005067/en/Innovative-SuperBowl-1st-Caps-Record-Daddy

Butler, N. (2014) Scanning the future: Mobile marketing beyond QR codes. Available online at: http://stoppress.co.nz/opinion/scanning-future-mobile-marketing-beyond-qr-codes (accessed on 31 August 2016).

Canadi, M., Höpken, W. and Fuchs, M. (2010) 'Application of QR codes in online travel distribution', Paper presented at the Information and Communication Technologies in Tourism 2010, Lugano, Switzerland.

Cho, C.-H. (2004) 'Effects of banner clicking and attitude toward the linked target ads on brandattitude and purchase-intention changes', Journal of Global Academy of Marketing Science, Vol. 14, No. 1, pp.1-16.

Chu, H.-K., Chang, C.-S., Lee, R.-R. and Mitra, N.J. (2013) 'Halftone QR codes', ACM Trans. Graph., Vol. 32, No. 6, pp.1-8. doi: 10.1145/2508363.2508408

Chung, H. and Zhao, X. (2004) 'Effects of perceived interactivity on web site preference and memory: role of personal motivation', Journal of Computer-Mediated Communication, Vol. 10, No. 1.

eMarketer (2012) Low Adoption for QR Codes Suggests Consumer Disinterest: Gaining access to discounts is the primary reason consumers want to scan $Q R$ codes. Available online at: http://www.emarketer.com/Article/Low-Adoption-QR-Codes-Suggests-ConsumerDisinterest/1009194?ecid=a6506033675d47f881651943c21c5ed4\#\&utm_source=buffer\&buff er_share $=4 \mathrm{db} 79$ (accessed on 31 August 2016).

Fortin, D. and Ballantine, P. (2009) 'Why the experimental method is the ideal tool for studying consumer research in online environments', International Journal of Internet Marketing and Advertising, Vol. 5, No. 4, pp.241-245.

Fortin, D.R. and Dholakia, R.R. (2005) 'Interactivity and vividness effects on social presence and involvement with a web-based advertisement', Journal of Business Research, Vol. 58, No. 3, pp.387-396. 


\section{D.R. Fortin and K. Surovaya}

FreeQRCodes (n.d.) Past, Present and Future of $Q R$ Codes. Available online at: http://www.freeqrcodes.org/history.php (accessed on 31 August 2016).

Griffith, E. (2016) Messaging Apps Are Making QR Codes a Thing Again. Available online at: http://fortune.com/2016/05/19/kik-snapchat-qr-code (accessed on 31 August 2016).

Guido, G. (2001) The Salience of Marketing Stimuli: An Incongruity-Salience Hypothesis on Consumer Awareness, Kluwer Academic Publishers, Norwell, Massachusetts, USA.

Hamidi, J. (2008) Sony: The Quantum Code. Available online at: http://cargocollective.com/ jamalhamidi\#Sony-The-Quantum-Code

Infosec (2015) Security Attacks via Malicious $Q R$ Codes. Available online at: http://resources. infosecinstitute.com/security-attacks-via-malicious-qr-codes (accessed on 31 August 2016).

Jackson, D.W. (2011) 'Thinking about technology - standard bar codes beware - smart phone users may prefer QR codes', Law Library Journal, Vol. 103, No. 1, pp.153-158.

Johnson, G.J., Gordon, C.B., II and Anand, K. (2006) 'Interactivity and its facets revisited: theory and empirical test', Journal of Advertising, Vol. 35, No. 4, pp.35-52. doi: 10.2307/20460754

Jong-Hyuok, J., Somerstein, R. and Eun Seon, K. (2012) 'Should i scan or should i go?: Young consumers' motivations for scanning QR code Advertising', International Journal of Mobile Marketing, Vol. 7, No. 3, pp.25-37.

Kim, J. and Yu, E.A. (2013) 'Exploring the effect of personal traits on advertising combining TV and the QR code', International Journal of Mobile Communication, Vol. 11, No. 3, pp.262-278.

Lamb, A. and Johnson, L. (2013) 'QR codes in the school library: a dozen practical uses', Teacher Librarian, Vol. 40, No. 3, pp.63-67.

Law, R. (2012) 'Using quick response codes for student interaction during lectures', Proceedings of the 17th ACM Annual Conference on Innovation and Technology in Computer Science Education, pp.401-401. doi: 10.1145/2325296.2325417

Lee, Y.H. (2000) 'Manipulating ad message involvement through information expectancy: effects on attitude evaluation and confidence', Journal of Advertising, Vol. 29, No. 2, pp.29-43. doi: $10.2307 / 4189140$

Lin, C.-H., Tsai, F.-Y., Tsai, W.-L., Wen, H.-W. and Hu, M.-L. (2012) 'The feasibility of QR-code prescription in Taiwan', Journal of Clinical Pharmacy and Therapeutics, Vol. 37, No. 6, pp.643-646.

Lin, Y.-S., Luo, S.-J. and Chen, B.-Y. (2013) 'Artistic QR code embellishment', Computer Graphics Forum, Vol. 32, No. 7, pp.137-146. doi: 10.1111/cgf.12221

Lisa, S. and Piersantelli, G. (2008) 'Use of 2D barcode to access multimedia content and the web from a mobile handset', Paper presented at the Global Telecommunications Conference, 2008. IEEE GLOBECOM 2008, IEEE New Orleans, LO

Liu, Y. and Shrum, L.J. (2002) 'What is interactivity and is it always such a good thing? Implications of definition, person, and situation for the influence of interactivity on advertising effectiveness', Journal of Advertising, Vol. 31, No. 4, pp.53-64. doi: $10.2307 / 4189237$

Liu, Y. and Shrum, L.J. (2009) 'A dual-process model of interactivity effects', Journal of Advertising, Vol. 38, No. 2, pp.53-68.

Lo, L., Coleman, J. and Theiss, D. (2013) 'Putting QR codes to the test', New Library World, Vol. 114, Nos. 11/12, pp.459-477.

Lubow, R.E. and Moore, A.U. (1959) 'Latent inhibition: the effect of nonreinforced pre-exposure to the conditional stimulus', Journal of Comparative and Physiological Psychology, Vol. 52, No. 4, pp.415-419. doi: 10.1037/h0046700

Mack, E. (2014) Yes, QR codes have a future! In holograms? Available online at: http://www.cnet.com/news/yes-qr-codes-have-a-future-in-holograms (accessed on 31 August 2016).

MacKenzie, S.B., Lutz, R.J. and Belch, G.E. (1986) 'The role of attitude toward the ad as a mediator of advertising effectiveness: a test of competing explanations', Journal of Marketing Research, Vol. 23, No. 2, pp.130-143. doi: 10.2307/3151660 


\section{Measuring the effects of visual scan codes in advertising}

Maddox, L.M. and Mehta, D. (1997) 'The role and effect of web addresses in advertising', Journal of Advertising Research, Vol. 37, No. 2, pp.47-59.

McMillan, S.J. and Hwang, J.-S. (2002) 'Measures of perceived interactivity: an exploration of the role of direction of communication, user control, and time in shaping perceptions of interactivity', Journal of Advertising, Vol. 31, No. 3, pp.29-42. doi: 10.2307/4189224

Michael, G.A. and Gálvez-García, G. (2011) 'Salience-based progression of visual attention', Behavioural Brain Research, Vol. 224, No. 1, pp.87-99.

Narang, S., Jain, V. and Roy, S. (2012) 'Effect of QR codes on consumer attitudes', International Journal of Mobile Marketing, Vol. 7, No. 2, pp.52-64.

O'Brien, C. (2016) Shazam Could Replace The $Q R$ Code. Available online at: http://thefutureofads.com/shazam-could-replace-the-qr-code (accessed on 31 August 2016).

Okazaki, S., Hirose, M. and Li, H. (2011) 'QR code mobile promotion: an initial inquiry', Advances in Advertising Research, Vol. 2, pp.405-420.

Okazaki, S., Li, H. and Hirose, M. (2012) 'Benchmarking the use of QR code in mobile promotion', Journal of Advertising Research, Vol. 52, No. 1, pp.102-117. doi: 10.2501/JAR52-1-1021117

Okazaki, S., Navarro-Bailón, M.Á. and Molina-Castillo, F.-J. (2012) 'Privacy concerns in quick response code mobile promotion: the role of social anxiety and situational involvement', International Journal of Electronic Commerce, Vol. 16, No. 4, pp.91-119.

Okazaki, S., Navarro, A. and Campo, S. (2013) 'Cross-media integration of QR code: a preliminary exploration', Journal of Electronic Commerce Research, Vol. 14, No. 2, pp.137-148.

Okazaki, S., Navarro, A. and López-Nicolas, C. (2013) 'Assessing gender differences in 'Quick Response' code loyalty promotion acceptance', The Service Industries Journal, Vol. 33, No. 12, pp.1165-1177.

O'Neill, E. (n.d.) 5 Reasons Why QR Codes Are Worse Than Useless. Available online at: $\mathrm{http}: / / \mathrm{www}$.sparkpage.com/5-reasons-why-qr-codes-are-worse-than-useless (accessed on 31 August 2016).

Ozcelik, E. and Acarturk, C. (2011) 'Reducing the spatial distance between printed and online information sources by means of mobile technology enhances learning: using 2D barcodes', Computers \& Education, Vol. 57, No. 3, pp.2077-2085.

Petro, G. (2014) How Proximity Marketing Is Driving Retail Sales. Available online at: http://www.forbes.com/sites/gregpetro/2014/10/08/how-proximity-marketing-is-driving-retailsales/\#5e83c2843ff5 (accessed on 3 September 2016).

QRCode (n.d.) History of $Q R$ Code. Available online at: http://www.qrcode.com/en/history (accessed on 31 August 2016).

Rafaeli, S. (1988) 'Interactivity: from new media to communication', Sage Annual Review of Communication Research: Advancing Communication Science, Vol. 16, pp.110-134, Sage, Beverly Hills, CA.

Rice, R. and Williams, F. (1984) 'Theories old and new: the study of new media', in R.R. Associates (Ed.): The New Media: Communication, Research and Technology, Sage, Beverly Hills, CA.

Riley, R. (2015) 'Shazam Widens Ways Retailers Can Serve Promos In-Store', eMarketer. Available online at: http://www.emarketer.com/Article/Shazam-Widens-Ways-RetailersServe-Promos-In-Store/1012008

Sago, B. (2011) 'The usage level and effectiveness of quick response (QR) codes for integrated marketing communication purposes among college students', International Journal of Integrated Marketing Communications, Vol. 3, No. 2, pp.7-17.

Savitz, E. (2012) Why QR Codes Don't Work. Available online at: http://www.forbes.com/ sites/ciocentral/2012/08/03/why-qr-codes-dont-work/\#626c14f8272f (accessed on 31 August 2016).

Schmidmayr, P., Ebner, M. and Kappe, F. (2008) 'What's the Power behind 2D Barcodes? Are They the Foundation of the Revival of Print Media?' Proceedings of I-Know'08 and I-Media'08, 6th International Conference on Knowledge Management and New Media Technology, pp.234-242. 


\section{D.R. Fortin and K. Surovaya}

Schneider, S. (2016) Why QR Codes are the Future of Wearable Devices. Available online at: https://uqr.me/blog/why-qr-codes-future-wearable-devices (accessed on 31 August 2016).

Schubö, A. (2009) 'Salience detection and attentional capture', Psychological Research, Vol. 73, pp.233-243.

Shin, D.-H., Jung, J. and Chang, B.-H. (2012) 'The psychology behind QR codes: user experience perspective', Computers in Human Behavior, Vol. 28, No. 4, pp.1417-1426.

Shop2mobi (2012) Tesco QR Code Virtual Store. Available online at: http://www.shop2mobi.com/ blog/tesco-qr-code-virtual-store (accessed on 31 August 2016).

Sparkes, M. (2015) 'Shazam to Begin Identifying Physical Objects', The Telegraph. Available online at: http:/www.telegraph.co.uk/technology/news/11454657/Shazam-to-beginidentifying-physical-objects.html

Steuer, J. (1992) 'Defining virtual reality: dimensions determining telepresence', Journal of Communication, Vol. 42, No. 4, pp.73-93. doi: 10.1111/j.1460-2466.1992.tb00812.x

Strout, A. (2013) The Death Of The $Q R$ Code. Available online at: http://marketingland.com/thedeath-of-the-qr-code-37902 (accessed on 31 August 2016).

Teo, H.-H., Oh, L.-B., Liu, C. and Wei, K.-K. (2003) 'An empirical study of the effects of interactivity on web user attitude', International Journal of Human-Computer Studies, Vol. 58, No. 3, pp.281-305.

Underwood, R.L. and Klein, N.M. (2002) 'Packaging as brand communication: effects of product pictures on consumer responses to the package and brand', Journal of Marketing Theory \& Practice, Vol. 10, No. 4, p.58.

van Dijk, W.W., Zeelenberg, M. and van der Pligt, J. (2003) 'Blessed are those who expect nothing: lowering expectations as a way of avoiding disappointment', Journal of Economic Psychology, Vol. 24, pp.505-516.

Veenis, M. (2012) QR-codes in Print Media Advertisements: The Effect of Exposure to a QR-code and Access to the Online Brand Platform on Advertisement Attitude, Brand Attitude and Purchase Intention, Master's degree thesis, University of Amsterdam.

Voss, K.E., Spangenberg, E.R. and Grohmann, B. (2003) 'Measuring the hedonic and utilitarian dimensions of consumer attitude', Journal of Marketing Research, Vol. 40, No. 3, pp.310-320. doi: 10.2307/30038861

Warner, L. and Franzen, R. (1947) 'Value of color in advertising', Journal of Applied Psychology, Vol. 31, No. 3, pp.260-270. doi: 10.1037/h0057772

Watson, C., McCarthy, J. and Rowley, J. (2013) 'Consumer attitudes towards mobile marketing in the smart phone era', International Journal of Information Management, Vol. 33, No. 5, pp.840-849.

Williams, F., Rice, R. and Rogers, E. (1988) Research Methods and the New Media, The Free Press, New York, NY.

Wilkerson, D. (2012) 5 Reasons QR Code Marketing Is Broken (and How to Fix It). Available online at: http://mashable.com/2012/05/17/reasons-qr-codes-are-broken/\#a_SlFYuh5sqg (accessed on 31 August 2016).

Wolfe, J.M. (2001) 'Guided search 4.0: a guided search model that does not require memory for rejected distractors', Journal of Vision, Vol. 1, No. 3, p.349. doi: 10.1167/1.3.349

$\mathrm{Wu}, \mathrm{G} ., \mathrm{Hu}, \mathrm{X}$. and $\mathrm{Wu}, \mathrm{Y}$. (2010) 'Effects of perceived interactivity, perceived web assurance and disposition to trust on initial online trust', Journal of Computer-Mediated Communication, Vol. 16, No. 1, pp.1-26.

Xue, D. and Hairong, L. (2008) 'Creative use of QR codes in consumer communication', International Journal of Mobile Marketing, Vol. 3, No. 2, pp.61-67.

Zhenhui, J., Chan, J., Tan, B.C.Y. and Wei Siong, C. (2010) 'Effects of interactivity on website involvement and purchase intention', Journal of the Association for Information Systems, Vol. 11, No. 1, pp.34-59. 